\title{
Identifying Differentially Expressed Genes in Pollen from Self-Incompatible "Wuzishatangju" and Self-Compatible "Shatangju" Mandarins
}

\section{Hongxia Miao ${ }^{1,2}$, Zixing Ye ${ }^{2}$, Jaime A. Teixeira da Silva ${ }^{3}$, Yonghua Qin ${ }^{2, *}$ and Guibing Hu ${ }^{1,2, *}$}

1 State Key Laboratory for Conservation and Utilization of Subtropical Agro-bioresources, College of Horticulture, South China Agricultural University, Guangzhou 510642, China; E-Mail: guibing@scau.edu.cn

2 Key Laboratory of Biology and Genetic Improvement of Horticultural Crops-South China of Ministry of Agriculture, College of Horticulture, South China Agricultural University, Guangzhou 510642, China; E-Mail: qinyh@scau.edu.cn

3 Faculty of Agriculture and Graduate School of Agriculture, Kagawa University, Ikenobe, Kagawa 761-0795, Japan; E-Mail: jaimetex@yahoo.com

* Authors to whom correspondence should be addressed; E-Mails: qinyh@scau.edu.cn (Y.Q.); guibing@scau.edu.cn (G.H.); Tel.: +86-20-8528-6905 (G.H.); Fax: +86-20-8528-2107 (G.H.).

Received: 14 January 2013; in revised form: 2 March 2013 / Accepted: 7 April 2013 /

Published: 17 April 2013

\begin{abstract}
Self-incompatibility (SI) is one of the important factors that can result in seedless fruit in Citrus. However, the molecular mechanism of SI in Citrus is not yet clear. In this study, two suppression subtractive hybridization (SSH) libraries (forward, F and reverse, R) were constructed to isolate differentially expressed genes in pollen from "Wuzishatangju" (SI) and "Shatangju" (self-compatibility, SC) mandarins. Four hundred and sixty-eight differentially expressed cDNA clones from 2077 positive clones were sequenced and identified. Differentially expressed ESTs are possibly involved in the SI reaction of "Wuzishatangju" by regulating pollen development, kinase activity, ubiquitin pathway, pollen-pistil interaction, and calcium ion binding. Twenty five SI candidate genes were obtained, six of which displayed specific expression patterns in various organs and stages after self- and cross-pollination. The expression level of the F-box gene (H304) and S1 (F78) in the pollen of "Wuzishatangju" was 5-fold higher than that in "Shatangju" pollen. The F-box gene, S1, UBE2, UBE3, RNaseHII, and PCP were obviously up-regulated in pistils at $3 \mathrm{~d}$ after self-pollination of "Wuzishatangju", approximately 3-, 2-, 10-, 5-, 5-, and 2-fold higher, respectively than that at the same stage after cross-pollination of "Wuzishatangju" $\times$
\end{abstract}


"Shatangju" pistils. The potential involvement of these genes in the pollen SI reaction of "Wuzishatangju" is discussed.

Keywords: Citrus reticulata Blanco; self-incompatibility (SI); suppression subtractive hybridization (SSH); pollen; expression analysis

\section{Introduction}

Self-incompatibility (SI) is a widespread mechanism in angiosperms which allows the pistil of a flower to reject self (genetically related) pollen, but to accept non-self (genetically unrelated) pollen for fertilization [1]. SI systems are categorized into sporophytic self-incompatibility (SSI) and gemetophytic self-incompatibility (GSI) according to the genetic control of pollen behavior. In the SSI system of Brassicaceae, growth of the pollen tube arrests at the surface of the stigma and a kinase-mediated signaling cascade is involved in the SI reaction [2]. In the GSI system of Rosaceae, Solanaceae, and Plantaginaceae, the arrest of growth of incompatible pollen tubes is in styles and its SI reaction is genetically controlled by style-expressed $S$-RNase ( $S$ locus-encoded Ribonuclease) genes [3] and pollen-expressed SFB (S-haplotype-specific F-box)/SLF (S-locus F-box) genes [4-6]. To date, style-expressed $S$-RNase genes have been isolated from the Solanaceae [7], Rosaceae [8], and Plantaginaceae [9]. However, pollen-expressed $S$ gene remains a myth. In 2000, a cDNA fragment of the pollen $S$ gene was first identified from Nicotiana alata and it was primarily expressed during pollen development [10]. Then, AhSLF-S $S_{2}$ (Antirrhinum hispanicum S-locus F-box of $S_{2}$-haplotype), a candidate pollen $S$-determinant gene [4], and $P i S L F_{2}\left(S_{2}\right.$-allele of Petunia inflata $S$-locus F-box) [11] were obtained from $P$. inflata. Currently, great progress has been made in cloning, expression and functional analysis of pollen-expressed $S F B / S L F$ genes from plum (Prunus mume; $S L F_{1}, S L F_{2}$, $S L F_{3}$ ) [12], almond (P. dulcis; $S F B a, S F B c$ ) [5], Japanese apricot (P. mume; $\left.S F B_{f}\right)$ [13], European apricot (P. armeniaca; $S F B c$ ) [14], sweet cherry (P. avium; $\left.S F B_{3}, S F B_{9}\right)$ [15], sour cherry (P. cerasus; $S F B_{13^{\prime}}$ ) [16], apple (Malus $\times$ domestica; $S L F_{1}, S L F_{2}$ ) [17], petunia (P. inflata; $\left.S L F_{2}, S L F_{b^{-}} S_{2}\right)[11,18]$, and Japanese pear (Pyrus pyrifolia; PpSFBB) [19].

Citrus belongs to the GSI system [20], and the study of SI in Citrus species is relevant not just because of the commercial impact (seedless fruit) it could have, but also for the understanding of SI systems evolution. GSI of Citrus is different from the GSI of model plants, and cytological analysis showed that the site of self-pollen tube inhibition was in the upper styles of "Commune" clementine (C. clementina Hort. ex Tan) [21], the lower one-third of styles of 29 Citrus cultivars [22], and the ovaries of "Guanxi" pomelo, "Duwei" pomelo (C. grandis) [23] and "Wuzishatangju" mandarin (C. reticulata Blanco) [24]. To date, style-expressed $R$ Nase activity genes have been obtained from Calamondin (C. reticulata var. austera $\times$ Fortunella sp.) [25], "Hirado Buntan" (C. grandis Osbeck) [26], "Zigui shatian" pummelo (C. grandis Osbeck) [27] and "Wuzishatangju" (C. reticulata Blanco) [28]. Recently, a full-length cDNA sequence of the ubiquitin-activating enzyme E1 (UBE1) gene was obtained from the pistils of "Wuzishatangju" (SI) and "Shatangju" (self-compatibility, SC) mandarins, in which five amino acids in cDNA and DNA sequences of UBE1 between "Wuzishatangju" and "Shatangju" differed, and in which the expression level of the UBE1 gene in "Shatangju" anthers 
was approximately 10-fold higher than that in the anthers of "Wuzishatangju" (SI) [29]. Compared to "Wuzishatangju", three amino acids were substituted in the cDNA of the $S_{1}$ self-incompatibility locus-linked pollen 3.15 gene $\left(S_{1-3.15}\right)$ from "Shatangju" (SC). The expression level of the $S_{1-3.15}$ gene in the ovaries of "Shatangju" was approximately 60-fold higher than that in the ovaries of "Wuzishatangju" [30]. Moreover, pistil-expressed SI-related genes such as $\mathrm{Ca}^{2+}$-binding protein, senescence-associated cysteine protease, and C2-domain containing protein, were isolated from SI "Wuzishatangju" mandarin [31,32]. However, differentially expressed pollen $S$ genes or other pollen SI-related factors in "Wuzishatangju" (SI) and "Shatangju" (SC) mandarins are still unknown.

"Wuzishatangju" (C. reticulata Blanco) (seedless, very tasty and easy-to-peel), derived from a bud mutation of a seedy cultivar "Shatangju", is one of the most popular mandarin cultivars in China. Our previous cytological studies showed that the seedlessness of "Wuzishatangju" results from GSI [24]. To explore the molecular mechanism of SI in "Wuzishatangju", two suppression subtractive hybridization (SSH) libraries were constructed to isolate pollen SI candidate genes using mature pollen of SI "Wuzishatangju" and SC "Shatangju". Expression characteristics of all SI candidate genes were analyzed using semi-quantitative RT-PCR (SqRT-PCR) and quantitative real-time PCR (qPCR). The aim of this study was to identify differentially expressed genes in pollen from self-incompatible "Wuzishatangju" and self-compatible "Shatangju" mandarins and to discuss the possible roles of the identified candidate genes in the SI response of "Wuzishatangju".

\section{Results}

\subsection{Identification of Gene Fragments from Two SSH Libraries}

Two SSH libraries were constructed to isolate differentially expressed genes from mature pollen of "Wuzishatangju" and "Shatangju" mandarins. According to the results from colony-PCR, a total of 2077 positive colonies (1050 from the forward SSH library (F) and 1027 from the reverse SSH library (R)) were obtained and the size of inserted cDNA fragments ranged from 300 to $1000 \mathrm{bp}$, although most were 400-700 bp (Figure S1). Based on reverse northern analysis, 230 clones from the F library were up-regulated in "Wuzishatangju" but down-regulated in "Shatangju" and 238 clones from the R library were up-regulated in "Shatangju" but down-regulated in "Wuzishatangju". Up-regulated clones were identified using the DIG-labeled cDNA from "Shatangju" and "Wuzishatangju" (Figure S2).

\subsection{General Statistics of Two SSH Libraries}

The 468 differentially expressed clones (230 from the F library and 238 from the R library) were sequenced (BGI, Shenzhen, China). After removing repeat sequences, 111 and 184 unique sequences were obtained from the F and R library, respectively. All these sequences (295) were compared with an available database to find similarities with known sequences. Dynamic translation (Blastx) was carried out and only matched sequences with an E-value lower than $10^{-3}$ were considered to be homologous sequences while sequences with an $E$-value higher than $10^{-3}$ were labeled as undescribed. Homologous sequences accounted for $59.6 \%$ of the sequences in the $\mathrm{F}$ library and for $67.4 \%$ in the R library (Table S1). Among the homologous sequences, 14 from the F library $(14 / 64,21.8 \%)$ and 25 from the R 
library $(25 / 117,21.4 \%)$ lacked annotation. Additionally, there were a total of 11 (six from the F library and five from the R library) no-mapping sequences. All of these data are summarized in Figure 1.

Figure 1. Gene distribution from two suppression subtractive hybridization (SSH) libraries. In the F library, self-incompatibility (SI) "Wuzishatangju" pollen was used as the "tester", and self-compatibility (SC) "Shatangju" as the "driver". In the R library, SC "Shatangju" pollen was used as the "tester", and SI "Wuzishatangju" as the "driver". The Arabic numerals represent the number of unique sequences at each step of the annotation process. NoBlast, no blast result; NoAnnot, no annotation; Annot, annotation. Data analysis and visualization of results were performed by the Blast2GO software.
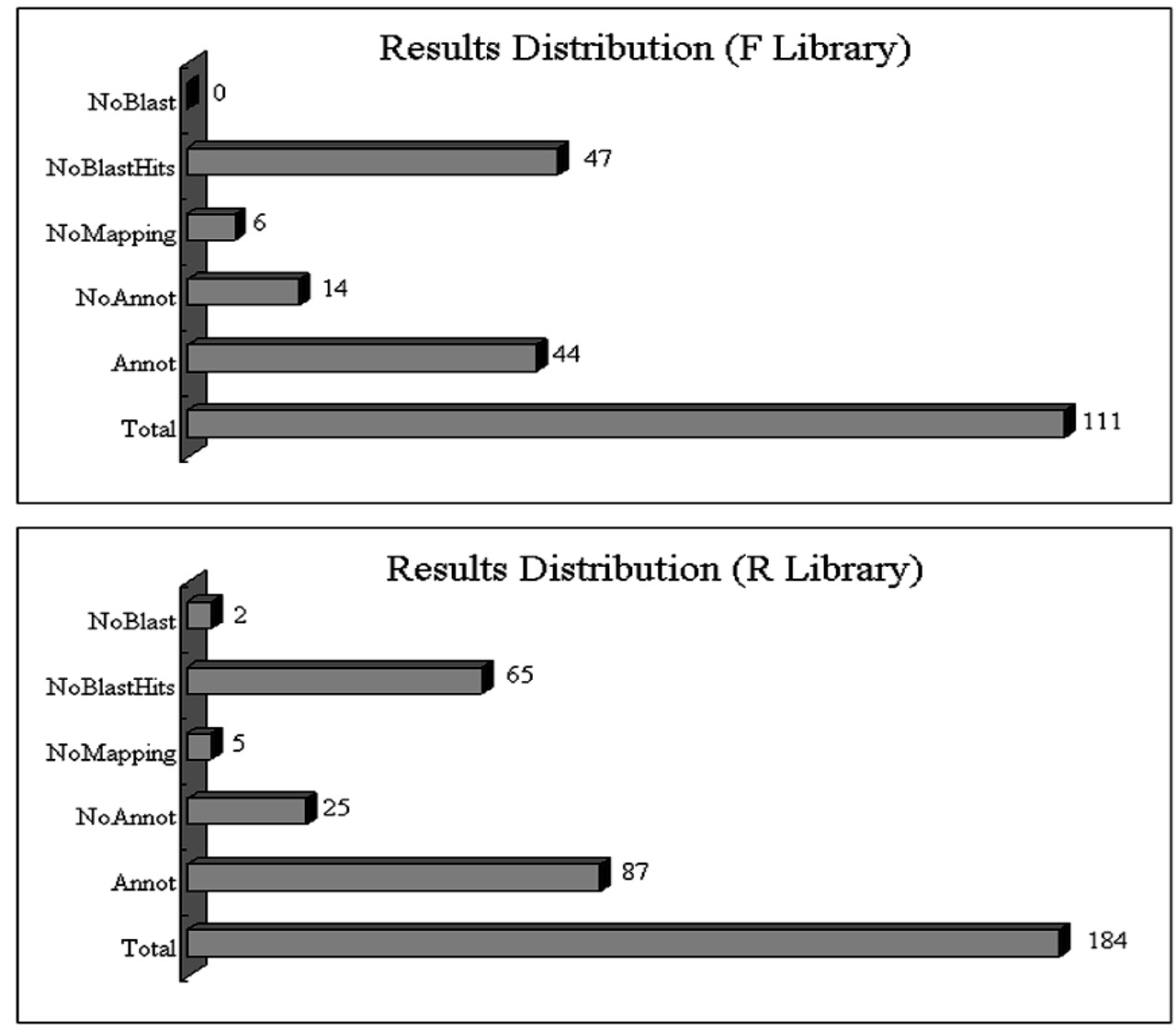

\subsection{Gene Ontology Analysis}

Gene ontology analysis was carried out using the blast2GO program and three ontological categories i.e., biological process (Figure 2 and Table S2), molecular function and cellular components were obtained (Figure S3). In the category of "biological process", the most frequent process was the metabolic process (27\% in the F library and $31 \%$ in the R library), followed by the cellular process ( $25 \%$ in the F library and 30\% in the R library) and localization (11\% in the F library and $15 \%$ in the R library). For the "molecular function", catalytic activity was the most frequent activity (53\% in the F library and $49 \%$ in the $\mathrm{R}$ library), followed by binding protein (30\% in the F library and $27 \%$ in the R library). Significant differences were observed in electron carrier activity (none in the F library and 1\% in the R library) and transcription regulator activity categories (11\% in the F library and $19 \%$ in the R library). For the "cellular component", the most frequent activity was cell (49\% in the F library and 50\% in the R 
library), followed by organelle (39\% in the F library and 37\% in the R library). The macromolecular complex was different (5\% in the $\mathrm{F}$ library and $10 \%$ in the $\mathrm{R}$ library) between the $\mathrm{F}$ library and the $\mathrm{R}$ library. According to the bioinformatics analysis, differentially expressed ESTs are possibly involved in the pollen SI reaction of "Wuzishatangju" through the regulation of pollen development, kinase activity, the ubiquitin pathway, the pollen-pistil interaction, sexual differentiation, and signal transduction (Table 1).

Figure 2. Classification of the unique sequence from the SSH according to Gene Ontology criteria. Gene Ontology analysis was carried out on the transcripts isolated from the two libraries. The graph, which combined biological processes, was made based on ontology level 2.

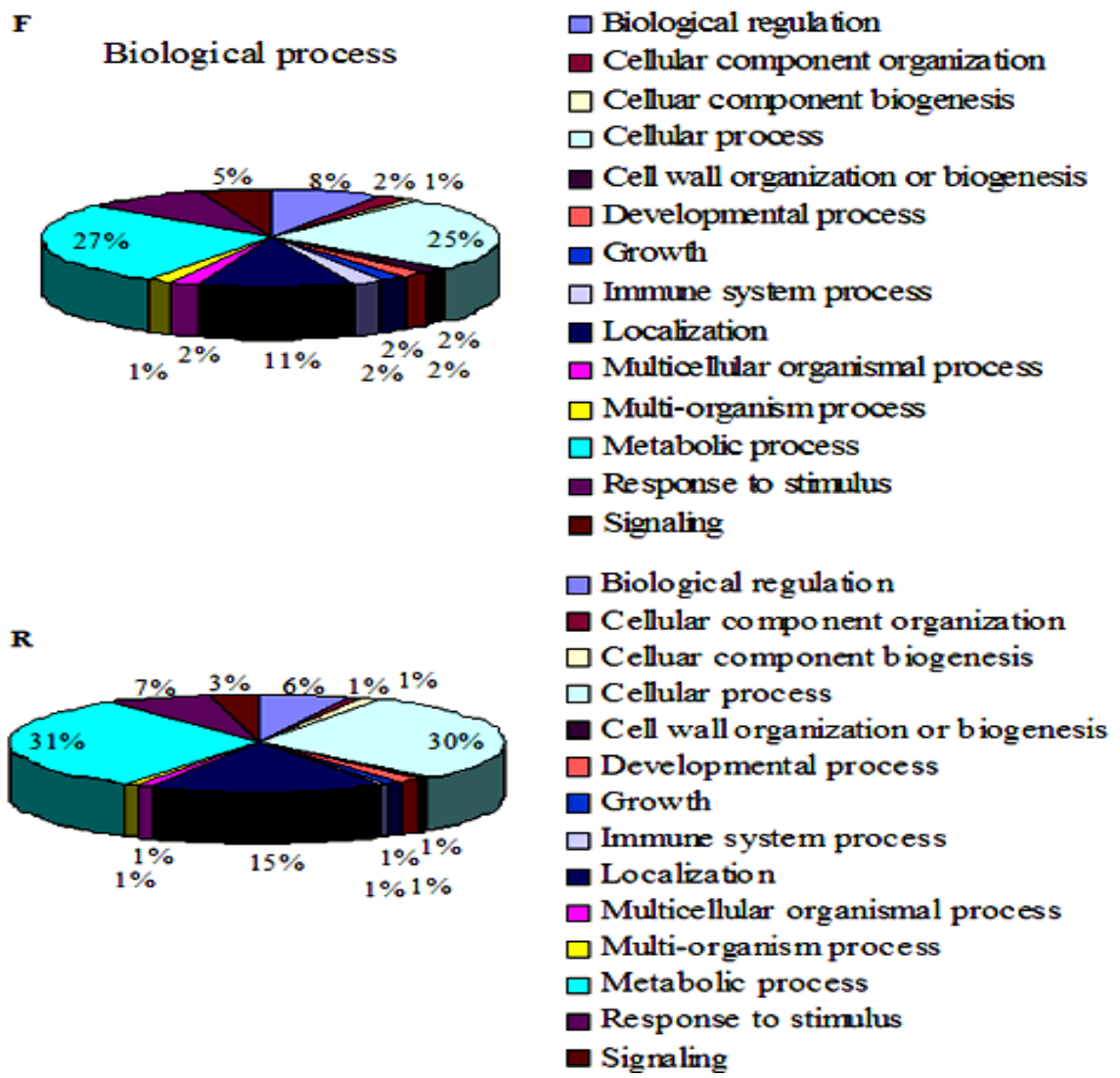

Table 1. All potential pollen self-incompatibility (SI)-related genes obtained from the F and R libraries.

\begin{tabular}{|c|c|c|c|c|c|c|}
\hline $\begin{array}{c}\text { Seq. } \\
\text { Name }\end{array}$ & Seq. Description & $\begin{array}{c}\text { GenBank } \\
\text { accession No. }\end{array}$ & $\begin{array}{c}\text { Length } \\
\text { (bp) }\end{array}$ & $E$-value & Similarity & Annotation \\
\hline \multicolumn{7}{|c|}{ F library } \\
\hline $\mathrm{H} 102$ & Pollen coat-like protein (PCP) & JK724775 & 488 & $2.23 \times 10^{-31}$ & $86.55 \%$ & Pollen development \\
\hline H115 & $\begin{array}{l}\text { Calcium-dependent } \\
\text { phospholipid binding protein } \\
(\mathrm{CPBP})\end{array}$ & JK724776 & 805 & $3.67 \times 10^{-112}$ & $86.40 \%$ & Calcium ion binding \\
\hline H128 & Pollen allergen Pla o1 & JK724777 & 526 & $1.80 \times 10^{-35}$ & $57.85 \%$ & Extracellular space \\
\hline $\mathrm{H} 264$ & Senescence-associated protein & JK724778 & 252 & $1.07 \times 10^{-36}$ & $89.95 \%$ & Biological process \\
\hline H304 & F-box protein (F-box) & JK724779 & 446 & $3.04 \times 10^{-23}$ & $87.80 \%$ & Kinase activity \\
\hline
\end{tabular}


Table 1. Cont.

\begin{tabular}{|c|c|c|c|c|c|c|}
\hline $\begin{array}{l}\text { Seq. } \\
\text { Name }\end{array}$ & Seq. Description & $\begin{array}{c}\text { GenBank } \\
\text { accession No. }\end{array}$ & $\begin{array}{c}\text { Length } \\
\text { (bp) }\end{array}$ & $E$-value & Similarity & Annotation \\
\hline \multicolumn{7}{|c|}{ F library } \\
\hline $\mathrm{H} 428$ & $\begin{array}{l}\text { Actin depolymerizing factor } \\
(\mathrm{ADF})\end{array}$ & JK724780 & 612 & $6.19 \times 10^{-85}$ & $93.75 \%$ & Cytoskeleton \\
\hline H543 & Zinc finger protein & JK724781 & 372 & $4.58 \times 10^{-33}$ & $69.80 \%$ & $\begin{array}{l}\text { Transcription factor } \\
\text { activity }\end{array}$ \\
\hline H556 & $\begin{array}{l}\text { Ubiquitin-protein ligase E3 } \\
\text { (UBE3) }\end{array}$ & JK724782 & 471 & $1.44 \times 10^{-62}$ & $95.00 \%$ & $\begin{array}{l}\text { CUL4 RING } \\
\text { ubiquitin ligase }\end{array}$ \\
\hline H858 & $\begin{array}{l}\text { Ubiquitin-conjugating enzyme } \\
\text { E2 (UBE2) }\end{array}$ & JK724783 & 314 & $1.58 \times 10^{-35}$ & $97.63 \%$ & ATP binding \\
\hline H1092 & $\begin{array}{l}\text { Vacuolar } \mathrm{H}^{+} \text {-translocating } \\
\text { inorganic pyrophosphatase }\end{array}$ & JK724784 & 808 & $1.33 \times 10^{-5}$ & $64.56 \%$ & $\begin{array}{l}\text { Inorganic } \\
\text { diphosphatase } \\
\text { activity }\end{array}$ \\
\hline \multicolumn{7}{|c|}{$\mathrm{R}$ library } \\
\hline F15 & Phospholipase & JK724785 & 248 & $7.28 \times 10^{-39}$ & $77.30 \%$ & $\begin{array}{l}\text { Serine/threonine } \\
\text { kinase activity }\end{array}$ \\
\hline F65 & $\begin{array}{l}\text { F-box and wd } 40 \text { domain } \\
\text { protein }\end{array}$ & JK724786 & 339 & $6.79 \times 10^{-52}$ & $82.15 \%$ & G-protein complex \\
\hline F78 & $\begin{array}{l}\text { Self-incompatibility S1 family } \\
\text { protein (S1) }\end{array}$ & JK724787 & 252 & $1.38 \times 10^{-9}$ & $62.83 \%$ & $\begin{array}{l}\text { Pollen-pistil } \\
\text { interaction }\end{array}$ \\
\hline F960 & $\begin{array}{l}\text { Sexual differentiation process } \\
\text { protein isp4-like (SDPP) }\end{array}$ & JK724788 & 840 & $7.23 \times 10^{-67}$ & $83.80 \%$ & Transporter activity \\
\hline F966 & $\begin{array}{l}\text { Seed maturation protein PM37 } \\
(\mathrm{SMP})\end{array}$ & JK724789 & 246 & $5.47 \times 10^{-26}$ & $87.90 \%$ & Biological process \\
\hline F1166 & $\begin{array}{l}\mathrm{Ca}^{2+} \text {-dependent } \\
\text { membrane-binding protein } \\
\text { annexin }\end{array}$ & JK724790 & 212 & $1.25 \times 10^{-16}$ & $87.50 \%$ & $\begin{array}{l}\text { Calcium-transporting } \\
\text { ATPase activity }\end{array}$ \\
\hline F1166 & $\begin{array}{l}\mathrm{Ca}^{2+} \text {-dependent } \\
\text { membrane-binding protein } \\
\text { annexin }\end{array}$ & JK724790 & 212 & $1.25 \times 10^{-16}$ & $87.50 \%$ & $\begin{array}{l}\text { Calcium-transporting } \\
\text { ATPase activity }\end{array}$ \\
\hline $\mathrm{F} 250$ & Alpha glucosidase & JK724791 & 478 & $9.75 \times 10^{-50}$ & $83.65 \%$ & Glucosidase activity \\
\hline F465 & $\begin{array}{l}\text { Ribonuclease HII family } \\
\text { protein (RNaseHII) }\end{array}$ & JK724792 & 344 & $6.15 \times 10^{-18}$ & $77.24 \%$ & $\begin{array}{l}\text { Ribonuclease } \mathrm{H} \\
\text { activity }\end{array}$ \\
\hline F499 & $\begin{array}{l}\text { Anther-specific protein } \\
\text { LAT52 precursor }\end{array}$ & JK724793 & 181 & $1.67 \times 10^{-6}$ & $70.80 \%$ & Extracellular space \\
\hline F519 & Actin 3 & JK724794 & 692 & $4.47 \times 10^{-134}$ & $99.50 \%$ & Cytoskeleton \\
\hline F546 & $\begin{array}{l}\text { Pollen allergen Che a } 1 \\
\text { precursor }\end{array}$ & JK724795 & 260 & $1.67 \times 10^{-14}$ & $64.50 \%$ & Extracellular space \\
\hline F1019 & Cell wall invertase (CWI) & JK724796 & 420 & $9.75 \times 10^{-50}$ & $83.65 \%$ & Hydrolase activity \\
\hline F580 & $\begin{array}{l}\text { Zinc finger (C2H2 type) } \\
\text { family protein }\end{array}$ & JK724797 & 373 & $3.65 \times 10^{-22}$ & $75.20 \%$ & $\begin{array}{l}\text { Transcription factor } \\
\text { activity }\end{array}$ \\
\hline F685 & Auxin-repressed protein & JK724798 & 595 & $1.18 \times 10^{-9}$ & $61.67 \%$ & Signal transduction \\
\hline F822 & $\begin{array}{l}\text { WD-40 repeat protein-like } \\
\text { (WD-40) }\end{array}$ & JK724799 & 465 & $6.61 \times 10^{-41}$ & $94.25 \%$ & G-protein complex \\
\hline
\end{tabular}




\subsection{Expression Analyses of SI Candidate Genes by SqRT-PCR}

Based on the SqRT-PCR analyses, 25 candidate genes (10 from the F library and 15 from the R library) were chosen for further analyses (Table S3). Among the 25 candidate genes, there are nine potential pollen-pistil/pollination process genes (Table S4). Results from SqRT-PCR showed that expression levels of the ubiquitin-conjugating enzyme E2 gene (UBE2) and a WD-40 repeat protein-like gene (WD-40) in pollen were lower than those of the other organs of "Wuzishatangju". The other 23 genes displayed a similar organ-specific and up-regulated pattern in the pollen of SI "Wuzishatangju". After self-pollination of "Wuzishatangju" and cross-pollination of "Wuzishatangju" × "Shatangju", 10 SI-related genes i.e., the F-box gene (H304), UBE2 (H858), UBE3 (H556), S1 (F78), RNaseHII (F465), SDPP (F960), PCP (H102), CPBP (H115), SMP (F966), and CWI (F1019) showed a time-specific expression pattern (Figure 3). The expression level of CPBP (H115) in pistils at $2 \mathrm{~d}$ after self-pollination of "Wuzishatangju" was higher than $2 \mathrm{~d}$ after cross-pollination of "Wuzishatangju" $\times$ "Shatangju". PCP (H102), the F-box gene (H304) and S1 (F78) were obviously up-regulated in pistils at $3 \mathrm{~d}$ after self-pollination of "Wuzishatangju". The highest expression level of SMP (F966) was detected in pistils at $6 \mathrm{~d}$ after self-pollination of "Wuzishatangju" while the lowest expression level was observed in pistils at $6 \mathrm{~d}$ after cross-pollination of "Wuzishatangju" $\times$ "Shatangju" (Figure 3).

Figure 3. Expression analysis of 10 pollen SI-related genes in different organs of "Wuzishatangju" and "Shatangju" mandarins using SqRT-PCR. CPBP, Calcium-dependent phospholipid binding protein; UBE2, Ubiquitin-conjugating enzyme E2; S1-protein, self-incompatibility S1 family protein; UBE3, Ubiquitin-protein ligase E3; PCP, Pollen coat-like protein; RNase HII, Ribonuclease HII family protein; SDPP, Sexual differentiation process protein; SMP, Seed maturation protein; CWI, Cell wall invertase. Data are based on $0.5 \mathrm{~g}$ of random samples collected from each organ.
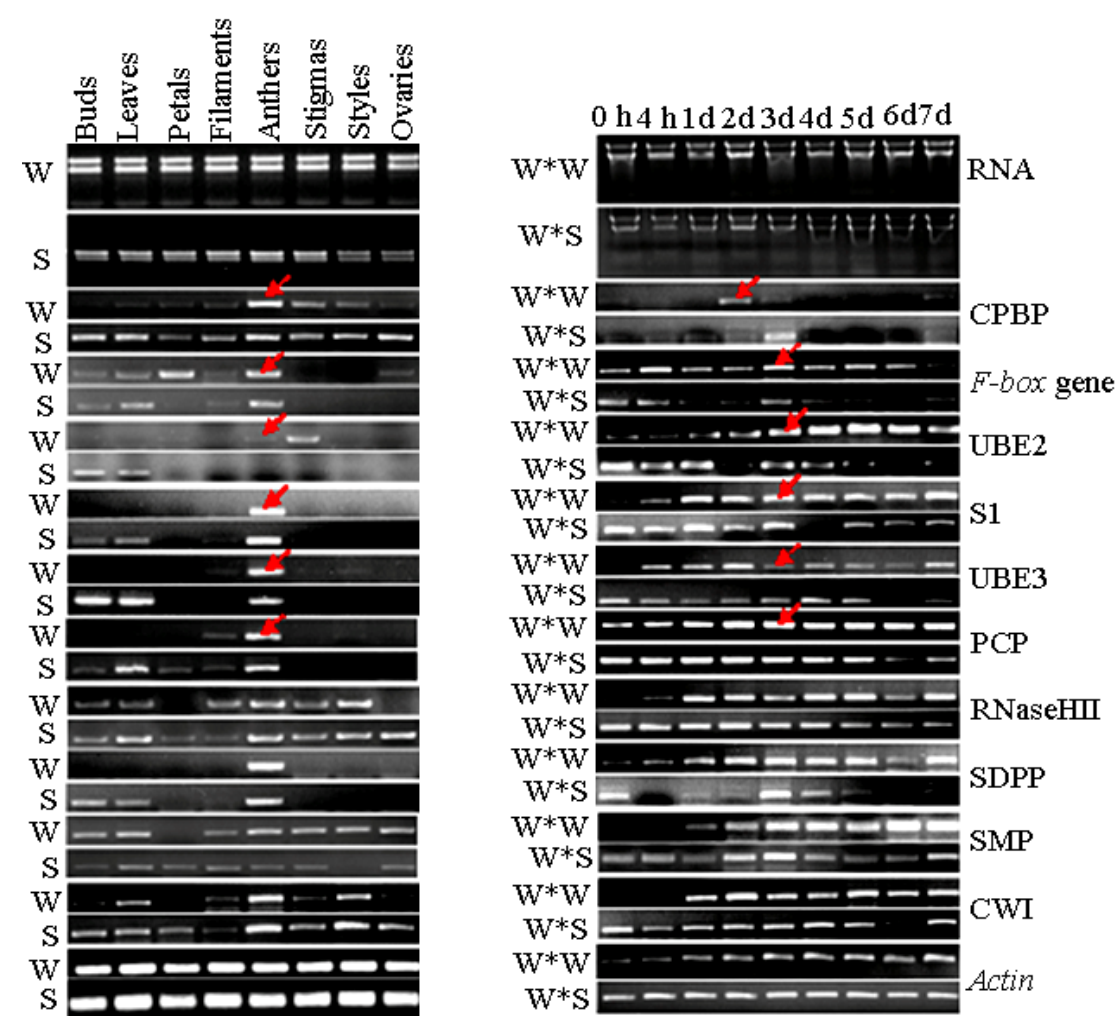
2.5. Expression Analyses of SI-Related Genes in Different Organs from "Wuzishatangju” and "Shatangju" Mandarins Using qPCR

Organ-specific expression patterns of 10 SI-related genes in different organs from "Wuzishatangju" and "Shatangju" were further analyzed using qPCR (Figure 4). The expression level of the $F$-box gene in petals and pollen of "Wuzishatangju" was 3- and 2-fold higher, respectively than that in the same organ of "Shatangju". A similar expression pattern of S1, RNase HII, and SDPP was detected in "Wuzishatangju" pollen, approximately 4-, 2-, and 3-fold higher, respectively than that in "Shatangju" pollen. The expression level of CPBP in the stigmas of "Wuzishatangju" was 4-fold higher than that in "Shatangju" stigmas. Compared to other organs, UBE3, PCP, and CWI were obviously up-regulated in pollen from "Wuzishatangju" and "Shatangju" mandarins.

Figure 4. Expression analysis of 10 pollen SI-related genes in different organs of "Wuzishatangju" and "Shatangju" mandarins using qPCR. CPBP, Calcium-dependent phospholipid binding protein; UBE2, Ubiquitin-conjugating enzyme E2; S1-protein, self-incompatibility S1 family protein; UBE3, Ubiquitin-protein ligase E3; PCP, Pollen coat-like protein; RNase HII, Ribonuclease HII family protein; SDPP, Sexual differentiation process protein; SMP, Seed maturation protein; CWI, Cell wall invertase. The error bars represent SD of three replicates. Data are based on $0.5 \mathrm{~g}$ of random samples collected from each organ.

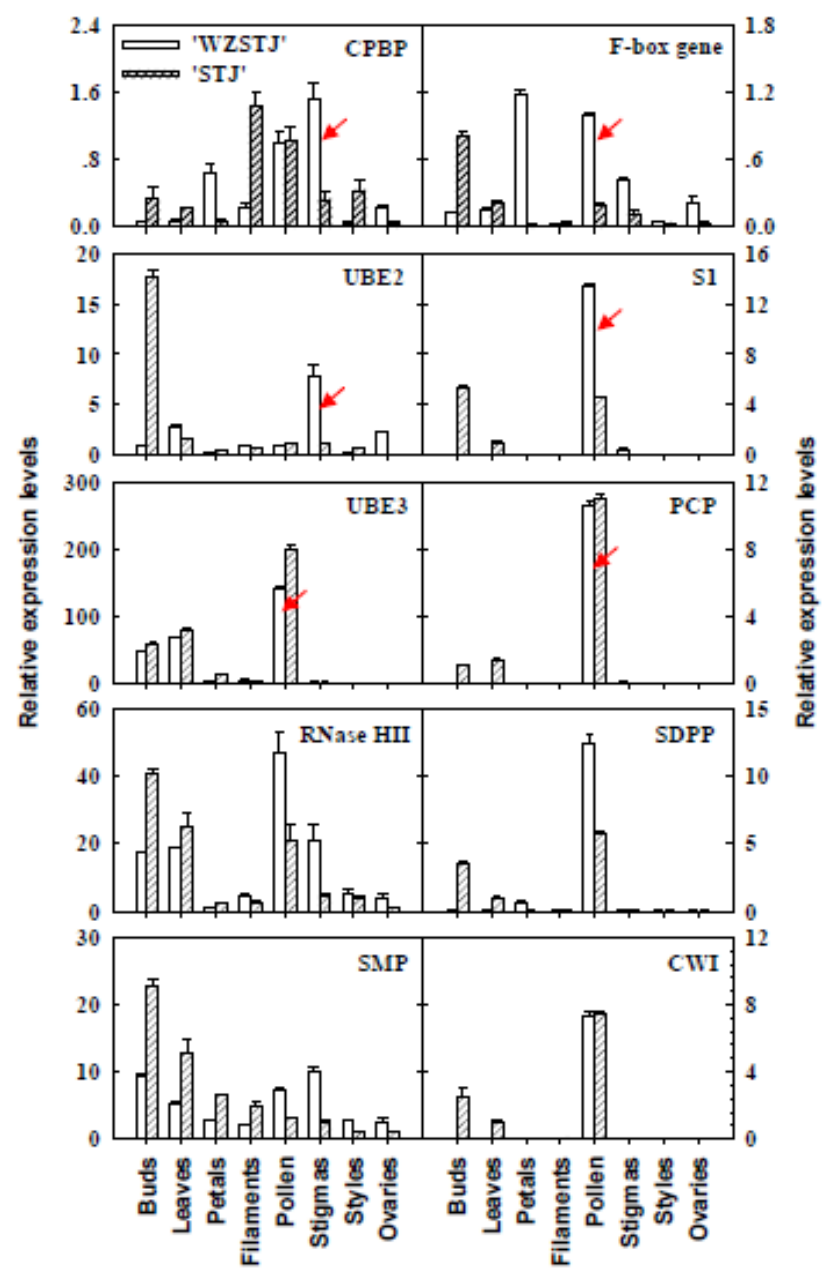


Figure 5. Expression analyses of 10 pollen SI-related genes in different stages of pistils after self-pollination of "Wuzishatangju" and cross-pollination of "Wuzishatangju" $\times$ "Shatangju" mandarins using qPCR. "W*W", self-pollination of "Wuzishatangju" $\times$ "Wuzishatangju"; "W*Y", cross-pollination of "Wuzishatangju" $\times$ "Shatangju". CPBP, Calcium-dependent phospholipid binding protein; UBE2, Ubiquitin-conjugating enzyme E2; S1-protein, self-incompatibility S1 family protein; UBE3, Ubiquitin-protein ligase E3; PCP, Pollen coat-like protein; RNase HII, Ribonuclease HII family protein; SDPP, Sexual differentiation process protein; SMP, Seed maturation protein; CWI, Cell wall invertase. The error bars represent the SD of three replicates. Data are based on $0.5 \mathrm{~g}$ of random samples collected from each organ.

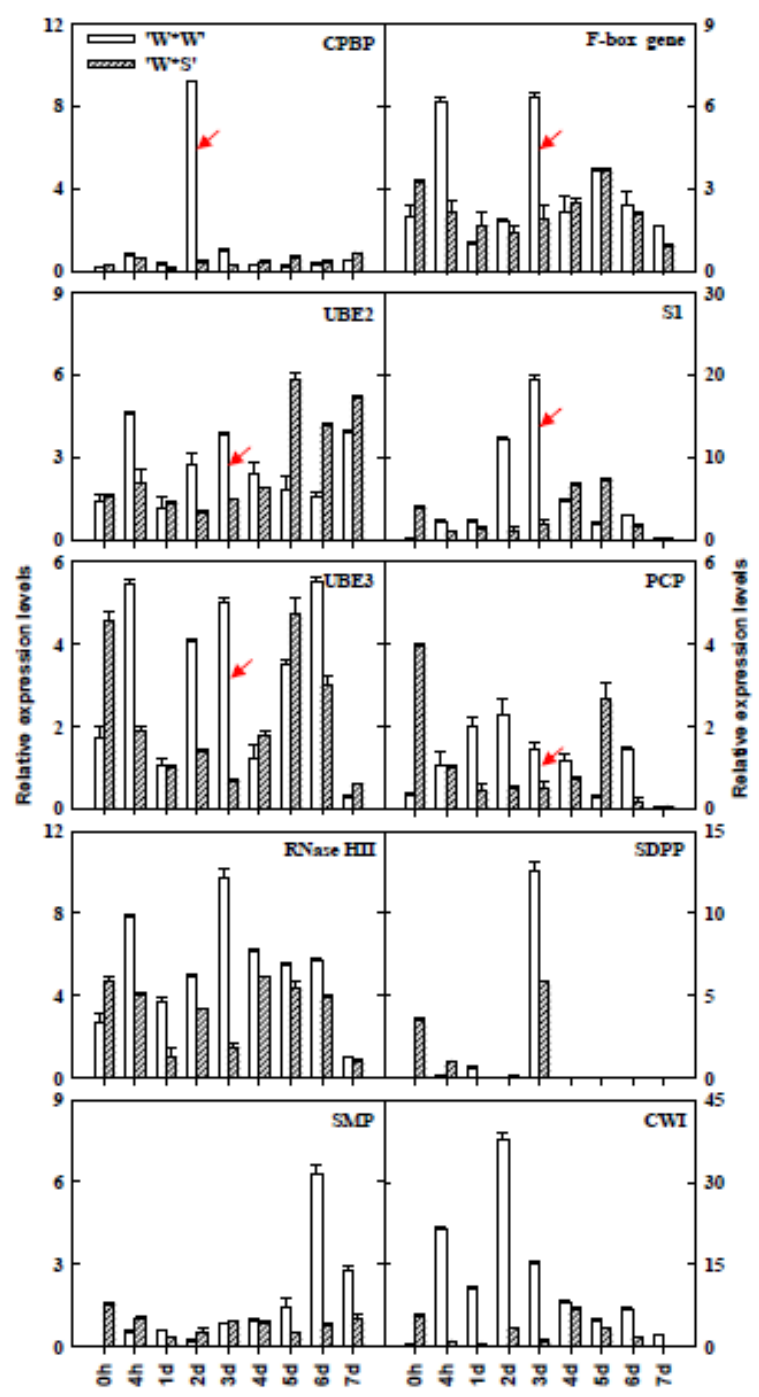

2.6. Expression Analyses of SI-Related Genes in Different Stages of the Pistil after Self-Pollination of "Wuzishatangju" and Cross-Pollination of "Wuzishatangju" × "Shatangju" Using qPCR

Time-specific expression patterns of 10 SI-related genes in different stages of pistils after self-pollination of "Wuzishatangju" and cross-pollination of "Wuzishatangju" $\times$ "Shatangju" were detected using qPCR (Figure 5). The highest expression levels of CPBP and CWI were detected in pistils at $2 \mathrm{~d}$ after self-pollination of "Wuzishatangju", and were approximately 30- and 40-fold higher than 
$2 \mathrm{~d}$ after cross-pollination of "Wuzishatangju" $\times$ "Shatangju", respectively. For self-pollinated pistils of "Wuzishatangju", a decrease in the expression level of S1 was observed at $0 \mathrm{~h}, 4 \mathrm{~h}, 1$ and $2 \mathrm{~d}$, followed by an increase at 3, 4 and $5 \mathrm{~d}$, and a decrease thereafter. Similar expression patterns of the $F$-box gene, UBE2, UBE3, PCP, RNase HII, and SDPP were detected in pistils at $3 \mathrm{~d}$ after self-pollination of "Wuzishatangju", resulting in 3-, 2-, 5-, 5-, 4-, and 2-fold higher expression than $3 \mathrm{~d}$ after cross-pollination of "Wuzishatangju" $\times$ "Shatangju", respectively. The expression level of SMP in pistils at $6 \mathrm{~d}$ after self-pollination of "Wuzishatangju" was 6-fold higher than $6 \mathrm{~d}$ after cross-pollination in pistils of "Wuzishatangju" $\times$ "Shatangju".

\section{Discussion}

SSH technology is an effective method to screen different expression SI-related genes between the control (the driver) and the experimental transcriptome (the tester) [31-33]. Pollen-pistil interactions are an essential prelude to fertilization in angiosperms and determine SI/SC [34]. In the pistil's SI response of "Wuzishatangju" mandarin, differentially expressed ESTs are possibly involved in the SI reaction through the regulation of the ubiquitin/26S proteasome pathway, the $\mathrm{Ca}^{2+}$-signaling pathway, receptor kinase, developmental processes, stimulus, or transcription [31]. Although pollen $S$ genes or SI-related factors in different species have been reported, how these genes operate in Citrus is unknown. In this study, two SSH libraries were constructed to identify differentially expressed genes in pollen from "Wuzishatangju" (SI) and "Shatangju" (SC) mandarins. Several SI candidate genes involved in the kinase activity (F-box gene, H304, accession No. JK724779), pollen-pistil interaction (Self-incompatibility S1 family protein (S1), F78, accession No. JK724787), ubiquitin pathway (Ubiquitin-conjugating enzyme E2 (UBE2), H858, accession No. JK724783; Ubiquitin-protein ligase E3 (UBE3), H556, accession No. JK724782), calcium ion binding (Calcium-dependent phospholipid binding protein (CPBP), H115, accession No. 724776), and pollen development (Pollen coat-like protein (PCP), H102, accession No. 724776) (Table 1) were obtained.

A large number of F-box genes were found in model species [4,5,12,17,35]. F-box genes play an important role in the regulation of a complex set of developmental events during floral development [36] and the SI reaction [37]. Higher expression levels of the $C g F-b o x$ were noted in the style, petals and anthers compared to low expression levels in the ovary and leaves of "Zigui shatian" pummelo (C. grandis Osbeck) [36]. In SI citrus clementina, a novel F-box gene showed a drastic up-regulation both in laser microdissected stylar canal cells and in self-pollinated whole styles with stigmas of "Comune", concomitant with the arrest of pollen tube growth [38]. In the Rosaceae, specific expression of SLF (S-locus F-box) genes in pollen was responsible for SI in P. dulcis [5], P. mume [12], and $P$. avium [17]. In the present study, an F-box gene (H304) was obtained whose expression was obviously up-regulated in pollen of SI "Wuzishatangju" (Figure 4), a pattern which mimics the expression of $S L F / S F B$ genes [12,17]. The highest expression of the F-box gene (H304) was found in pistils at $3 \mathrm{~d}$ after self-pollination of "Wuzishatangju" (Figure 5), which was consistent with our previous findings in which $3 \mathrm{~d}$ was the crucial period for a shift from a self-compatible to a self-incompatible state [28], implying that the F-box gene may be involved in the pollen development or SI response of "Wuzishatangju" mandarin. 
S1 (F78) has putative S1 protein activity in SI and shared 55\% amino acid homology with the SI S1 family protein from Arabidopsis thaliana (NP 196221) (Table S2). In Papaver rhoeas, the S1 protein exhibits specific pollen inhibitory activity in vitro. Pollen carrying the S1 allele is inhibited while pollen not carrying S1 is not inhibited [39]. However, S1 has not yet been documented in Citrus. In the present study, S1 (F78) showed obvious up-regulated expression in pollen (Figure 4) and in pistils $3 \mathrm{~d}$ after self-pollination of "Wuzishatangju" (Figure 5) which was similar to the expression pattern of the F-box gene (Figure 5). These results suggest that S1 (F78) may be a SI S1 family protein member involved in the pollen inhibitory activity of "Wuzishatangju" mandarin.

The general function of the ubiquitination pathway i.e., ubiquitin-activating enzyme E1 (UBE1), UBE2 and UBE3 is to mediate protein degradation by the ubiquitin/26S proteosome pathway [40]. UBE1 first activates ubiquitin by covalently attaching the molecule to its active site cysteine residue, then UBE2 serves as an ubiquitin-carrier enzyme and performs the second step in the ubiquitination reaction; finally, UBE3 binds the target protein substrate and transfers ubiquitin from E2 cysteine to a lysine residue on the target protein [41]. The arm repeat-containing 1 (ARC1) and the skp1-cull-F-box (SCF) proteins, belonging to the UBE3 family, are involved in SSI and GSI responses, respectively [40]. ARC1 plays a positive role during the SI response. Antisense suppression of ARC1 in SI W1 plants of Brassica napus resulted in a partial breakdown of SI, demonstrating that these ARC1 antisense W1 plants had a functional $S$-locus protein, 11/S-locus Cys-rich (SP11/SCR) [42]. Qiao et al. [43] found that $A h S L F-S_{2}$ physically interacts with $S$-RNases in a non-allele-specific fashion probably through a proposed SCF ${ }^{\mathrm{AhSLF}-\mathrm{S} 2}$ (Skp1/Cull or CDC53/F-box) complex that targets $S$-RNase destruction during a compatible rather than an incompatible response in Antirrhinum hispanicum. In our study, UBE2 (H858) and UBE3 (H556) were obtained from the F library (Table 1). Higher expression levels of UBE3 (H556) were detected in pollen of "Wuzishatangju" (Figure 4), indicating a specific function to regulate the pollen SI response through the ubiquitin/26S proteosome pathway. Compared to other candidate genes, UBE2 (H858) showed down-regulated expression in pollen (Figure 4), suggesting that they may be involved in the ubiquitination pathway in the pollen of "Wuzishatangju" mandarin.

$\mathrm{Ca}^{2+}$ can regulate pollen tube growth in the GSI system of Papaver rhoeas and the inhibition of pollen tube growth is correlated with elevated free calcium levels in the incompatible pollen tubes [44]. $\mathrm{Ca}^{2+}$-dependent protein kinases could lead to $S$-RNase phosphorylation [45] and pollen-tube polarity growth [46] in the GSI system of Nicotiana alata. In the SSI system of Brassica, $\mathrm{Ca}^{2+}$-binding protein is predominantly expressed in pistils and anthers and plays an important role in pollen-pistil recognition, pollen tube growth, and fertilization [47]. OSPBP1 (Oryza sativa C2-domanin phospholipid-binding protein) has calcium concentration-dependent phospholipid-binding activity and is required for pollen fertility likely by regulating $\mathrm{Ca}^{2+}$ and phospholipid signaling pathways [48]. In this study, higher expression levels of CPBP (H115) were noted in pollen and stigmas of "Wuzishatangju" (Figure 3) as well as $2 \mathrm{~d}$ after self-pollination of "Wuzishatangju" pistils (Figure 4), which was consistent with the expression pattern of OsPBP1 in Oryza sativa [48], implying that the CPBP are likely to act as a $\mathrm{Ca}^{2+}$ and phospholipid signaling factor to inhibit pollen tube growth and pollen fertilization of "Wuzishatangju" mandarin.

PCP putatively has a self-pollen rejection function and interacts with the male determining $S$ specificity. It is essential for the rejection of incompatible pollen grains in the SI response of Brassica species [49]. SP11/SCR (S-locus protein 11 or $S$-locus Cys-rich) is the sole male determinant of SI in the 
Brassica genus and the $S_{8}$-SP11 protein product of $S P 11$ transgenic plants was present in the tapetum, pollen, and pollen of late developmental stages [50]. Currently, 22 alleles of SP11/SCR have been identified and all of them encode proteins with similar characteristics to those of predicted pollen coat protein (PCP) family proteins (small, basic Cys-rich proteins). In our study, the highest expression level of PCP (H102) was detected in mature pollen of "Wuzishatangju" (Figure 3) and $2 \mathrm{~d}$ after self-pollination in the pistil of "Wuzishatangju" (Figure 4). In our previous study, we found that pollen tube growth was blocked at $3 \mathrm{~d}$ after self-pollination in "Wuzishatangju" [24]. These results suggest that PCP is likely to act as a male determining factor to inhibit self-pollen tube growth in "Wuzishatangju" mandarin.

Four candidate SI genes i.e., RNase HII (F465), SDPP (F960), CWI (F1019), and SMP (F966) were also obtained (Table 1). RNase HII belongs to the RNases $H$ type 2 family and shows putative RNase activity to degrade the RNA moiety of RNA-DNA hybrids [51]. SDPP putatively transcribes, specifically during sexual development, to control sexual reproduction of female and male flowers in dioecious plants [52]. CWI represents a putative function in sucrose partitioning between source and sink organs which could result in a block during the early stages of pollen development in tobacco [53]. SMP, encoding a putative group 1 late embryogenesis abundant (LEA) protein, is involved in the synthesis of late-maturing soybean seeds [54]. However, the relationship between these genes and the occurrence of the SI reaction is unclear. In this study, RNase HII, SDPP, and CWI were up-regulated in "Wuzishatangju" pollen (Figure 3). The highest expression level of SMP (F966) was observed $6 \mathrm{~d}$ after self-pollination in pistils of "Wuzishatangju" (Figure 4).

A high percentage of undescribed sequences (54.1\%) were also obtained from the SSH (Table S1). This circumstance can account for the relatively high percentage of undescribed sequences encountered. Another reason to explain this high percentage may be that some ESTs could correspond to $3^{\prime}$ or $5^{\prime}$ untranslated regions (UTRs) which make it impossible to find homologues in available databases. However, most of these undescribed sequences can be classified as novel genes related to the SI reaction because only a few homologous genes related to SI have been identified.

\section{Experimental Section}

\subsection{Plant Materials}

Flower buds $(1.0 \mathrm{~cm} \times 0.5 \mathrm{~cm})$ were collected from six-year-old trees of "Wuzishatangju" (six trees) and "Shatangju" mandarins (four trees) in an orchard of South China Agricultural University. Buds, leaves, petals, filaments, stigmas, styles, ovaries, pistils, and anthers were collected separately using tweezers and frozen immediately in liquid nitrogen and stored at $-80{ }^{\circ} \mathrm{C}$ until later analysis. Mature pollen was used to construct SSH cDNA libraries, while the other organs were used for expression analyses of SI-related genes. Pistils of $0 \mathrm{~h}$ and $4 \mathrm{~h}$, and $1 \mathrm{~d}, 2 \mathrm{~d}, 3 \mathrm{~d}, 4 \mathrm{~d}, 5 \mathrm{~d}, 6 \mathrm{~d}$ and $7 \mathrm{~d}$ after artificial self-pollination of "Wuzishatangju" and cross-pollination of "Wuzishatangju" $\times$ "Shatangju" were collected, immediately frozen in liquid nitrogen and stored at $-80^{\circ} \mathrm{C}$ for expression analysis.

\subsection{Total RNA Extraction and mRNA Purification}

Total RNA was extracted from mature pollen of "Wuzishatangju" and "Shatangju" according to Luo et al. [55] and pretreated with RNase-free DNase I (TaKaRa, Dalian, China). The quality and 
concentration of RNA were examined by ethidium bromide (EB)-stained 1.2\% $(w / v)$ agarose gel electrophoresis and spectrophotometry (Bio-RAD, Hercules, CA, USA). Two $\mu \mathrm{g}$ of mRNA were purified from total RNA using a PolyAttract ${ }^{\circledR}$ mRNA Isolation System Kit III (Promega, Madison, WI, USA).

\subsection{Construction of SSH Libraries}

First-strand cDNAs were synthesized from about $2.0 \mu \mathrm{g}$ of mRNA sample using AMV reverse transcriptase. Second-strand cDNAs were generated using $\mathrm{T}_{4}$ DNA polymerase, then digested with $R s a$ I, and ligated to different adaptors. Forward subtraction was carried out using cDNA from mature pollen of "Wuzishatangju" as the "tester" and cDNA from mature pollen of "Shatangju" as the "driver". Reverse subtraction was performed using cDNA from mature pollen of "Shatangju" mandarin as the "tester" and cDNA from mature pollen of "Wuzishatangju" as the "driver" according to the manufacturer's instructions (Clontech PCR-Select ${ }^{\mathrm{TM}}$ cDNA Subtractive Kit; TaKaRa, Dalian, China) following the procedure of Miao et al. [32].

\subsection{Screening of SSH Libraries Using Colony-PCR and Reverse Northern Analysis}

Inserted fragments were screened by colony-PCR using M13 primers (M13-F: 5'-GAGCGGATAAC AATTTCACACAGG-3'; M13-R: 5'-CGCCAGGGTTTTCCCAGTCACGAC-3') (TaKaRa, Dalian, China). PCR was performed in a $25.0 \mu \mathrm{L}$ reaction mixture containing $1 \times$ PCR buffer, $0.1 \mathrm{mM} \mathrm{dNTPs}$, $0.4 \mu \mathrm{M}$ M13 primers, and 1.0 U rTaq DNA polymerase (TaKaRa, Dalian, China). The PCR parameters were: $94{ }^{\circ} \mathrm{C}$ for 4 min then 35 cycles of $94{ }^{\circ} \mathrm{C}$ for $40 \mathrm{~s}, 55^{\circ} \mathrm{C}$ for $40 \mathrm{~s}$ and $72{ }^{\circ} \mathrm{C}$ for $1.5 \mathrm{~min}$, with a final $72{ }^{\circ} \mathrm{C}$ for $10 \mathrm{~min}$. The quality and concentration of colony-PCR products were examined by EB-stained $1.0 \%(w / v)$ agarose gel electrophoresis and spectrophotometry (Bio-RAD, Hercules, CA, USA).

Reverse northern analysis was further carried out to screen up-regulated clones using the method of Miao et al. [32].

\subsection{Bioinformatics Analysis of Expressed Sequence Tags (ESTs)}

The nucleotide sequences of individual clones that exhibited up-regulated expression in the $\mathrm{F}$ and $\mathrm{R}$ libraries were sequenced according to the hybridization signal of reverse northern screening. All vector sequences were removed using VecScreen software in the National Center for Biotechnology Information (NCBI). All contigs and singlets were annotated according to the GO classification and the hierarchical structure using the Blast2GO suite. The Blast2Go program, which assigns the GO terms based on the BLAST definitions, was applied with an $E$-value $<10^{-3}$. If a transcript was annotated with more than one GO category, it was split equally among them. Ten ESTs from the F library and 15 ESTs from the R library were registered in GenBank (Table 1).

\subsection{Expression Analysis of SI-Related Genes by SqRT-PCR and $q P C R$}

Total RNA was extracted from various organs using the plant RNAout Kit (TIANDZ, Beijing, China). First-strand cDNA was synthesized in a $20.0 \mu \mathrm{L}$ reaction mixture using $1.0 \mu \mathrm{g}$ of total RNA 
from each sample by an Oligo(dT) $)_{18}$ primer and a Reverse Transcriptase M-MLV Kit according to the manufacturer's instructions (TaKaRa, Dalian, China).

Specific primer pairs were designed for all SI candidate genes from the F and R libraries (Table S5) using Primer 5.0 software. The expression patterns of all candidate genes were first studied by SqRT-PCR using a pair of primers (Actin-F: 5'-CACACTGGAGTGATGGTTGG-3' and Actin-R: 5'-ATTGGCCTTGGGGTTAAGAG-3') as an internal control to normalize samples. Expression levels of candidate genes were quantified by qPCR in an iQ5 real-time PCR detection system (Bio-Rad, Hercules, CA, USA) using the SYBR ExScript RT-PCR Kit (TaKaRa, Dalian, China). A sample of $25.0 \mu \mathrm{L}$ of the qPCR reaction volume contained $12.5 \mu \mathrm{L} \mathrm{SYBR}^{\circledR}$ Premix ExTaq ${ }^{\mathrm{TM}}$ (TaKaRa, Dalian, China), $1.0 \mu \mathrm{L}$ of each forward and reverse primers $(5.0 \mu \mathrm{M}), 8.5 \mu \mathrm{L} \mathrm{ddH_{2 }} \mathrm{O}$, and $2.0 \mu \mathrm{L}$ cDNA (40 ng). Actin-F and Actin-R primers were used to amplify the citrus actin gene (accession No. GU911361) as a loading control to normalize samples in separate tubes. Controls (actin gene) and all SI candidate genes were run in triplicate and repeated twice (technical replicates). Relative expression levels of these genes were calculated using the $2^{-\Delta \Delta C T}$ method [56]. Data were analyzed using iQ5 software in an iQ5 real-time PCR detection system (Bio-Rad, Hercules, CA, USA).

\section{Conclusion}

SSH approach is a useful tool to identify differently expressed genes in pollen from SI "Wuzishatangju" and SC "Shatangju" mandarins. Six candidate genes i.e., an F-box gene (H304), UBE2 (H858), UBE3 (H556), S1 (F78), CPBP (H115), and PCP (H102) were obtained and their temporal and spatial expression characteristics were explored. Up-regulated expression of the six genes in pollen and in pistils at $3 \mathrm{~d}$ after self-pollination of "Wuzishatangju" shows that they are possibly involved in the SI reaction of "Wuzishatangju" mandarin. Further research will be necessary to elucidate why the different expression levels of these genes could result in the SI reaction of "Wuzishatangju".

\section{Acknowledgements}

This work was supported by the National Natural Science Foundation of China (No. 31000899), a Research Fund for the Doctoral Program of Higher Education of China (No. 20104404120015 and 20114404110018), Guangdong Province Science Foundation of China (No. 06025843), Science and Technology Planning Project of Guangzhou (No. 2010r1-C771), Key Laboratory of Innovation and Utilization for Germplasm Resources in Horticultural Crops in Southern China of Guangdong Higher Education Institutes, South China Agricultural University (No. KBL11008).

\section{Conflict of Interest}

The authors declare no conflict of interest.

\section{References}

1. De Nettancourt, D. Incompatibility in angiosperms. Sex Plant Reprod. 1997, 10, 185-199. 
2. Takayama, S.; Shimosato, H.; Shiba, H.; Funato, M.; Che, F.S.; Watanabe, M.; Iwano, M.; Isogai, A. Direct ligand-receptor complex interaction controls Brassica self-incompatibility. Nature 2001, 413, 534-538.

3. McClure, B.; Cruz-García, F.; Romero, C. Compatibility and incompatibility in $S$-RNase-based systems. Ann. Bot. 2011, 108, 647-658.

4. Lai, Z.; Ma, W.; Han, B.; Liang, L.; Zhang, Y.; Hong, G.; Xue, Y. An F-box gene linked to the self-incompatibility $(S)$ locus of Antirrhinum is expressed specifically in pollen and tapetum. Plant Mol. Biol. 2002, 50, 29-41.

5. Ushijima, K.; Sassa, H.; Dandekar, A.M.; Gradziel, T.M.; Tao, R.; Hirano, H. Structural and transcriptional analysis of the self-incompatibility locus of almond: Identification of a pollen-expressed F-box gene with haplotype-specific polymorphism. Plant Cell 2003, 15, 771-781.

6. Kubo, K.; Entani, T.; Takara, A.; Wang, N.; Fields, A.M.; Hua, Z.; Toyoda, M.; Kawashima, S.; Ando, T.; Isogai, A.; et al. Collaborative non-self recognition system in S-RNase-based self-incompatibility. Science 2010, 330, 796-799.

7. Meng, X.; Sun, P.; Kao, T.H. S-RNase-based self-incompatibility in Petunia inflata. Ann. Bot. 2010, 253, 1-10.

8. Tao, R.; Iezzoni, A.F. The S-RNase-based gametophytic self-incompatibility system in Prunus exhibits distinct genetic and molecular features. Sci. Hortic. 2010, 124, 423-433.

9. Liang, L.; Huang, J.; Xue, Y. Identification and evolutionary analysis of a relic S-RNase in Antirrhinum. Sex Plant Reprod. 2003, 16, 17-22.

10. Li, J.; Nass, N.; Kusaba, M.; Dodds, P.N.; Treloar, N.; Clarke, A.E.; Newbigin, E. A genetic map of the Nicotiana alata $S$ locus that includes three pollen-expressed genes. Theor. Appl. Genet. 2000, 100, 956-964.

11. Sijacic, P.; Wang, X.; Skirpan, A.L.; Wang, Y.; Dowd, P.E.; McCubbin, A.G.; Huang, S.; Kao, T.H. Identification of the pollen determinant of S-RNase-mediated self-incompatibility. Nature 2004, 429, 302-305.

12. Entani, T.; Iwano, M.; Shiba, H.; Che, F.S.; Isogai, A.; Takayama, S. Comparative analysis of the self-incompatibility ( $S$-) locus region of Prunus mume: Identification of a pollen-expressed F-box gene with allelic diversity. Genes Cells 2003, 8, 203-213.

13. Ushijima, K.; Yamane, H.; Watari, A.; Kakehi, E.; Ikeda, K.; Hauck, N.R.; Iezzoni, A.F.; Tao, R. The $S$ haplotype-specific $F$-box protein gene, $S F B$, is defective in self-compatible haplotypes of Prunus avium and P. mume. Plant J. 2004, 39, 573-586.

14. Vilanova, S.; Badenes, M.L.; Burgos, L.; Martínez-Calvo, J.; Llácer, G.; Romero, C. Self-compatibility of two apricot selections is associated with two pollen-part mutations of different nature. Plant Physiol. 2006, 142, 629-641.

15. Sonneveld, T.; Tobutt, K.R.; Vaughan, S.P.; Robbins, T.P. Loss of pollen-S function in two self-compatible selections of Prunus avium is associated with deletion/mutation of an $S$ haplotype-specific F-box gene. Plant Cell 2005, 17, 37-51.

16. Hauck, N.R.; Yamane, H.; Tao, R.; Iezzoni, A.F. Accumulation of nonfunctional S-haplotypes results in the breakdown of gametophytic self-incompatibility in tetraploid prunus. Genetics $\mathbf{2 0 0 6}$, $172,1191-1198$. 
17. Cheng, J.; Han, Z.; Xu, X.; Li, T. Isolation and identification of the pollen-expressed polymorphic F-box genes linked to the $S$-locus in apple (Malus $\times$ domestica). Sex Plant Reprod. 2006, 19, 175-183.

18. Fields, A.M.; Wang, N.; Hua, Z.; Meng, X.; Kao, T.H. Functional characterization of two chimeric proteins between a Petunia inflata S-locus F-box protein, PiSLF 2 , and a PiSLF-like protein, PiSLFb-S 2 . Plant Mol. Biol. 2010, 74, 279-292.

19. Okada, K.; Tonaka, N.; Taguchi, T.; Ichikawa, T.; Sawamura, Y.; Nakanishi, T.; Takasaki-Yasuda, T. Related polymorphic F-box protein genes between haplotypes clustering in the BAC contig sequences around the S-RNase of Japanese pear. J. Exp. Bot. 2011, 62, 1887-1902.

20. Soost, R.K. Self-incompatibility in Citrus grandis Osbeck. J. Am. Soc. Hortic. Sci. 1964, 84, 137-140.

21. Distefano, G.; Caruso, M.; Malfa, S.L.; Gentile, A.; Tribulato, E. Histological and molecular analysis of pollen-pistil interaction in clementine. Plant Cell Rep. 2009, 28, 1439-1451.

22. Ngo, B.X.; Wakana, A.; Kim, J.H.; Mori, T.; Sakai, K. Estimation of self-incompatibility $S$ genotypes of Citrus cultivars and plants based on controlled pollination with restricted number of pollen grains. J. Fac. Agr. Kyushu Univ. 2010, 55, 67-72.

23. Wang, P.; Lü, L. Self-incompatible reaction parts in Citrus grandis "Guanximiyou" and "Duweimiyou"-Observation of pollination on different pistil parts in vitro. Chin. J. Trop. Crops 2009, 30, 1105-1108.

24. Ye, W.; Qin, Y.; Ye, Z.; Teixeira da Silva, J.A.; Zhang, L.; Wu, X.; Lin, S.; Hu, G. Seedless mechanism of a new mandarin cultivar "Wuzishatangju" (Citrus reticulata Blanco). Plant Sci. 2009, 177, 19-27.

25. Roiz, L.; Goren, R.; Shoseyov, O. Stigmatic RNase in calamondin (Citrus reticulata var. austera $\times$ Fortunella sp.). Physiol. Plantarum. 1995, 94, 585-590.

26. Kim, J.H.; Mori, T.; Wakana, A.; Ngo, B.X.; Masuda, J.; Sakai, K.; Kajiwara, K. Production of homozygous $S_{l}$ seedlings for $S$ gene in "Hirado Buntan" pummelo (Citrus grandis Osbeck) and determination of the $S$ alleles $\left(S_{9}\right.$ and $S_{10}$ ) by pollination with the $S_{1}$ seedlings to Citrus cultivars. J. Fac. Agr. Kyushu U. 2010, 55, 239-245.

27. Chai, L.; Ge, X.; Xu, Q.; Deng, X. CgSL2, an S-like RNase gene in "Zigui shatian" pummelo (Citrus grandis Osbeck), is involved in ovary senescence. Mol. Biol. Rep. 2011, 38, 1-8.

28. Miao, H.; Qin, Y.; Teixeira da Silva, J.A.; Ye, Z.; Hu, G. Cloning and expression analysis of S-RNase homologous gene in Citrus reticulata Blanco cv. Wuzishatangju. Plant Sci. 2011, 180, 358-367.

29. Miao, H.; Qin, Y.; Ye, Z.; Hu, G. Molecular characterization and expression analysis of ubiquitin-activating enzyme E1 gene in Citrus reticulate. Gene 2013, 513, 249-259.

30. Miao, H.; Qin, Y.; Ye, Z.; Hu, G. Molecular characterization and expression analysis of S1 self-incompatibility locus-linked pollen 3.15 gene in Citrus reticulata. J. Integr. Plant Biol. 2013, doi:10.1111/jipb.12026.

31. Miao, H.; Qin, Y.; Teixeira da Silva, J.A.; Ye, Z.; Hu, G. Identification of differentially expressed genes in pistils from self-incompatible Citrus reticulata by suppression subtractive hybridization. Mol. Biol. Rep. 2013, 40, 159-169. 
32. Miao, H.; Qin, Y.; Teixeira da Silva, J.A.; Ye, Z.; Hu, G. Isolation and differential expression analysis of self-compatibility-related genes from mature pistils of "Shatangju" mandarin (Citrus reticulata Blanco). J. Hortic. Sci. Biotech. 2011, 86, 575-582.

33. Yang, B.; Thorogood, D.; Armstead, I.P.; Franklin, F.C.H.; Barth, S. Identification of genes expressed during the self-incompatibility response in perennial ryegrass (Lolium perenne L.). Plant Mol. Biol. 2009, 70, 709-723.

34. Allen, A.M.; Thorogood, C.J.; Hegarty, M.J.; Lexer, C.; Hiscock, S.J. Pollen-pistil interactions and self-incompatibility in the Asteraceae: New insights from studies of Senecio squalidus (Oxford ragwort). Ann. Bot. 2011, 108, 687-698.

35. Wheeler, D.; Newbigin, E. Expression of 10 S-class SLF-like genes in Nicotiana alata pollen and its implications for understanding the pollen factor of the $S$ locus. Genetics 2007, 177, 2171-2180.

36. Chai, L.; Ge, X.; Biswas, M.K.; Deng, X. Molecular analysis and expression of a floral organ-relative F-box gene isolated from "Zigui shatian" pummelo (Citrus grandis Osbeck). Mol. Biol. Rep. 2011, 38, 4429-4436.

37. McClure, B. Darwin's foundation for investigating self-incompatibility and the progress toward a physiological model for S-RNase-based SI. J. Exp. Bot. 2009, 60, 1069-1081.

38. Caruso, M.; Merelo, P.; Distefano, G.; La Malfa, S.; Lo Piero, A.R.; Tadeo, F.R.; Talon, M.; Gentile, A. Comparative transcriptome analysis of stylar canal cells identifies novel candidate genes implicated in the self-incompatibility response of Citrus clementina. BMC Plant Biol. 2012, 12, doi:10.1186/1471-2229-12-20.

39. Foote, H.C.; Ride, J.P.; Franklin-Tong, V.E.; Walker, E.A.; Lawrence, M.J.; Franklin, F.C. Cloning and expression of a distinctive class of self-incompatibility (S) gene from Papaver rhoeas L. Proc. Natl. Acad. Sci. USA 1994, 91, 2265-2269.

40. Moon, J.; Parry, G.; Estelle, M. The ubiquitin-proteasome pathway and plant development. Plant Cell 2004, 16, 3181-3195.

41. Nandi, D.; Tahiliani, P.; Kumar, A.; Chandu, D. The ubiquitin-proteasome system. J. Biosci. 2006, 31, 137-155.

42. Stone, S.L.; Anderson, E.M.; Mullen, R.T.; Goring, D.R. $\mathrm{ARC}_{1}$ is an $\mathrm{E}_{3}$ ubiquitin ligase and promotes the ubiquitination of proteins during the rejection of self-incompatible Brassica pollen. Plant Cell 2003, 15, 885-898.

43. Qiao, H.; Wang, F.; Zhao, L.; Zhou, J.; Lai, Z.; Zhang, Y.; Robbins, T.P.; Xue, Y. The F-box protein $A h S L F-S_{2}$ controls the pollen function of S-RNase-based self-incompatibility. Plant Cell 2004, 16, 2307-2322.

44. Franklin-Tong, V.E.; Hackett, G.; Hepler, P.K. Ratio-imaging of $\mathrm{Ca}^{2+}{ }_{\mathrm{i}}$ in the self-incompatibility response in pollen tubes of Papaver rhoeas. Plant J. 1997, 12, 1375-1386.

45. Kunz, C.; Chang, A.; Faure, J.; Clarke, A.E.; Polya, G.M.; Anderson, M.A. Phosphorylation of style S-RNase by $\mathrm{Ca}^{2+}$-dependent protein kinases from pollen tubes. Sex Plant Reprod. 1996, 9 , 25-34.

46. Myers, C.; Romanowsky, S.M.; Barron, Y.D.; Garg, S.; Azuse, C.L.; Curran, A.; Davis, R.M.; Hatton, J.; Harmon, A.C.; Harper, J.F. Calcium-dependent protein kinases regulate polarized tip growth in pollen tubes. Plant J. 2009, 59, 528-539. 
47. Roberts, D.M.; Harmon, A.C. Calcium-modulated proteins: Targets of intracellular calcium signals in higher plants. Annu. Rev. Plant Biol. 1992, 43, 375-414.

48. Yang, W.; Lai, Y.; Li, M.; Xu, W.; Xue, Y. A novel C2-domain phospholipid-bind protein, OsPBP1, is required for pollen fertility in rice. Mol. Plant 2008, 1, 770-785.

49. Doughty, J.; Dixon, S.; Hiscock, S.J.; Willis, A.C.; Parkin, I.A.; Dickinson, H.G. PCP-A1, a defensin-like Brassica pollen coat protein that binds the $S$ locus glycoprotein, is the product of gametophytic gene expression. Plant Cell 1998, 10, 1333-1347.

50. Shiba, H.; Takayama, S.; Iwano, M.; Shimosato, H.; Funato, M.; Nakagawa, T.; Che, F.S.; Suzuki, G.; Watanabe, M.; Hinata, K.; et al. A pollen coat protein, SP11/SCR, determines the pollen $S$-specificity in the self-incompatibility of Brassica species. Plant Physiol. 2001, 125, 2095-2103.

51. Itaya, M. Isolation and characterization of a second RNase H (RNase HII) of Escherichia coli $\mathrm{K}_{-12}$ encoded by the rnhB gene. Proc. Natl. Acad. Sci. USA 1990, 87, 8587-8591.

52. Bracale, M.; Galli, M.G.; Falavigna, A.; Soave, C. Sexual differentiation in Asparagus officinalis L. Sex Plant Reprod.1990, 3, 23-30.

53. Engelke, T.; Hirsche, J.; Roitsch, T. Anther-specific carbohydrate supply and restoration of metabolically engineered male sterility. J. Exp. Bot. 2010, 61, 2693-2706.

54. Lee, P.; Chow, T.; Chen, Z.; Hsing, Y. Genomic nucleotide sequence of a soybean seed maturation protein GmPM9 gene. Plant Physiol. 1992, 100, 2121-2122.

55. Luo, M.; Xiao, Y.; Hou, L.; Luo, X.; Li, D.; Pei, Y. Cloning and expression analysis of a LIM-domain protein gene from cotton (Gossypium hirsutum L.). Acta Genetica Sin. 2003, 30, $175-182$.

56. Livak, K.J.; Schmittgen, T.D. Analysis of relative gene expression data using real-time quantitative PCR and the $2^{-\triangle \Delta C T}$ method. Methods 2001, 25, 402-408.

(C) 2013 by the authors; licensee MDPI, Basel, Switzerland. This article is an open access article distributed under the terms and conditions of the Creative Commons Attribution license (http://creativecommons.org/licenses/by/3.0/). 